University at Albany, State University of New York

Scholars Archive

2012

\title{
Adverse Childhood Experiences (ACEs), Service Use, and Service Helpfulness Among People Experiencing Homelessness
}

Heather Larkin Holloway

University at Albany, State University of New York, hlarkin@albany.edu

Jihyun Park

Follow this and additional works at: https://scholarsarchive.library.albany.edu/ssw_sw_scholar

Part of the Social Work Commons

\section{Recommended Citation}

Larkin Holloway, Heather and Park, Jihyun, "Adverse Childhood Experiences (ACEs), Service Use, and Service Helpfulness Among People Experiencing Homelessness" (2012). Social Welfare Faculty Scholarship. 3.

https://scholarsarchive.library.albany.edu/ssw_sw_scholar/3

This Article is brought to you for free and open access by the Social Welfare at Scholars Archive. It has been accepted for inclusion in Social Welfare Faculty Scholarship by an authorized administrator of Scholars Archive. For more information, please contact scholarsarchive@albany.edu. 


\title{
Adverse Childhood Experiences (ACEs), Service Use, and Service Helpfulness Among People Experiencing Homelessness
}

\author{
Heather Larkin \& Jihyun Park
}

\begin{abstract}
This study examines categories of adverse childhood experiences (ACEs) and service use backgrounds among a convenience sample of people experiencing homelessness ( $N=224)$, using logistic regression analysis $(n=174)$ and descriptive and comparative analyses. Eighty-seven percent reported at least 1 of 10 ACEs prior to age 18. Over half (53.2\%) reported 4 or more ACEs. Approximately half reported parental loss, emotional neglect, living with a substance abuser, and emotional abuse. ACEs were significantly correlated with one another. Among those who used prior services, ACEs predicted interpersonal prevention, clinical, and criminal justice services for emotional or substance abuse problems. Most indicated services were helpful. This study provides data for policy and program leaders to ensure at-risk families and communities have access to responsive services.
\end{abstract}

\section{IMPLICATIONS FOR PRACTICE}

- Social workers are encouraged to examine ACEs in psychosocial assessments.

- ACE-informed programs are proposed to reduce homelessness and break intergenerational ACE transmission.

- $\quad$ Restorative Integral Support (RIS) develops ACEinformed programs that integrate interventions to mobilize resilience and recovery.

$\mathrm{T}$ he social work profession is characterized by an integrative view that attends to the whole person within the context of social relationships (Garner, 2011; Germain \& Gitterman, 1980; Starnino, 2009; Thomas, 2004). This perspective helps to understand and address the complex and pervasive problem of homelessness, which arises out of individual and societal dynamics (Larkin \& Records, 2007). The current empirical study is the first to explore both a full range of adverse childhood experiences (ACEs) and service use prior to becoming homeless among a convenience sample of people experiencing homelessness. The ACE Study was designed in 1994 by medical researchers at Kaiser Permanente and the Centers for Disease Control and Prevention (CDC). An ACE Score is derived by adding the number of "yes" responses to any of the following 10 categories (not incidents) prior to the age of 18: physical abuse; emotional abuse; sexual abuse; domestic violence; growing up with a substance abusing household member; living with a mentally ill/suicidal household member; experiencing the incarceration of a household member; loss of a parent; emotional neglect; or physical neglect (Felitti et al., 1998). Burt (2001) suggests that ACEs increase individual vulnerability to societal circumstances such as poverty and lack of affordable housing. Similarly, Green (2005) set forth the idea that numerous devastating life events can end in an observable outcome of inability to maintain stable housing. Research is needed to better understand the role of early adversity in homelessness as well as services to prevent homelessness for at-risk groups. The current study uses logistic regression analysis to demonstrate the relationship between ACE categories and service use prior to becoming homeless. Descriptive analyses of ACE categories and respondents' perception of the helpfulness of services used are presented.

Burt (2001) cited the ACE Study to connect earlier adversity with the multiple problems common among people experiencing homelessness. ACE Study findings from a sample of 17,421 middle-class adults demonstrated a graded, or "dose-response," relationship between ACE Score and a number of later-life health risks and conditions. For example, higher ACE Scores were strongly associated with sexual risk behaviors, obesity, current smoking, substance abuse, depression, and suicide attempts, as well as lung, heart, and liver disease. The ACE Study authors proposed that risk behaviors, such as substance abuse or overeating, were often personal solutions that were adopted in response to a lack of healthier environmental resources and developed into serious health and social problems. Since health risk behaviors in parents can become an ACE for their children, intergenerational ACE transmission might be prevented through the provision of services that facilitate recovery (Larkin, Felitti, \& Anda, in press).

Social work researchers have yet to explore the full range of ACE Study categories among disadvantaged groups. Zlotnick, Tam, and Robertson (2004) found that substance abuse among homeless adults was influenced by adverse childhood events (see also Tam, Zlotnick, \& Robertson, 2003). Kim, Ford, Howard, and Bradford (2010) found an association between trauma and mental 
health problems among men experiencing homelessness. One study found that most of those experiencing homelessness and participating in co-occurring disorders treatment reported a history of physical or sexual abuse (Christensen et al., 2005). Qualitative research has shown a cumulative impact of family disorganization, abuse, poverty, and trauma in the lives of women experiencing homelessness and mental illness (Padgett, Hawkins, Abrams, \& Davis, 2006). Herman, Susser, Struening, and Link (1997) found that physical abuse, sexual abuse, and inadequate parental care constituted risks for homelessness. This handful of studies connects homelessness to some types of adversity and trauma, pointing to the need to thoroughly examine ACEs among this group.

If ACEs and later-life correlates are associated with homelessness, an understanding of service use prior to becoming homeless could point to opportunities to address ACEs to prevent homelessness. Yet, there is limited service use research, reflecting another gap relevant to ACE research and social work. For example, interviews disclosed that people living on the streets often perceive services as inadequate or inaccessible (Freund \& Hawkins, 2004). Substance abuse played a role in engagement with supports and services by people experiencing homelessness (Tam et al., 2003; Zlotnick et al., 2004). Organizational characteristics influenced services used by people experiencing homelessness (North, Pollio, Perron, Eyrich, \& Spitznagel, 2005). Research on systems integration sought to improve service access (Rosenheck et al., 2002). The current study seeks to address two gaps by exploring both ACE categories and service use history among people experiencing homelessness.

\section{Conceptual Framework}

Social workers have an opportunity to bring a person-inenvironment perspective to the ACE Study, integrating ecosystems theory with an appreciation of culture and psychological development (Germain \& Gitterman, 1980; Larkin, 2006; Robbins, Chatterjee, \& Canda, 2012). ACEs and subsequent health risk behaviors, intergenerationally transmitted, may be detrimental to development and become a risk for homelessness (Burt, 2001; Larkin, Felitti, \& Anda, in press; Larkin \& Records, 2007). Wilber (2000) demonstrates that development unfolds in multiple ways within the context of culture and systems (Robbins, Chatterjee, \& Canda, 2012). Inadequate cultural, systemic, and developmental resources to manage ACEs may contribute to adoption of health risk behaviors. For example, if a child lacks the developmental capacity and appropriate support to process an ACE, a solution of using substances to feel better could turn into a health risk. Risk behaviors, or ACE correlates such as depression, in parents are often ACEs for the next generation. This helps explain how service interventions that prevent ACEs or their consequences could reduce later-life homelessness as well as intergenerational ACE transmission (Larkin \& Records, 2007).

\section{Study Design and Methods}

The current research makes an original contribution to risk factors for homelessness by asking people currently experiencing homelessness about the full range of ACE categories, as well as exploring history of service use prior to becoming homeless and perceptions of service helpfulness. This cross-sectional study, approved by a university institutional review board (IRB), was designed to better understand common ACE and service use characteristics of people experiencing homelessness by asking: (a) How common are ACEs in the current sample? (b) Are the ACE categories inter-related? (c) Are ACEs associated with prior service use? (d) Were services considered helpful?

\section{Participants}

Participation was offered to people at four homeless service programs from 2007-2010, resulting in a sample of 224. Convenience sampling and a very brief questionnaire were used due to the challenging nature of data collection among people experiencing crisis and multiple problems in a busy setting. Front-line staff were provided an IRB-approved project-specific training to administer the informed consent and questionnaire. They introduced the study and expected time frame, emphasizing that participation was voluntary and would not affect service provision. Incentives were not included in the research. The study was introduced after completion of routine intake procedures. The study was not introduced to anyone judged by staff to be in an immediate crisis, under the influence of substances, or behaving disruptively.

\section{Setting}

Participants were recruited from four homeless service agencies and one homeless drop-in center in northern California (CA) and the capital region of New York (NY). The participating agencies in both areas provide comprehensive services, including temporary housing, basic needs, peer support, and case management. Both locations have a predominantly White population (CA, 84\%; NY 63\%; U.S. Census, 2010a, 2010b). A small city, the economy of the CA setting is characterized by agribusiness, tourism, and telecommunications (Key to the City, 2011). The economy of the NY setting centers around higher education, state government, technological industry, and health care (Capital District, 2011).

\section{Data Collection}

Data collection began with adults served by a CA homeless services agency in 2007 and a NY agency in 2008, continuing into 2010. The informed consent process included three levels of participation. People were first 
asked if they consented to the questionnaire. A second consent was sought to gather demographic and substance abuse history information from their chart. A third consent asked whether the researcher could gather follow-up information about substance abuse, mental health, or other conditions influencing the resident's behavior while in the program. The survey was administered in a private space and temporarily stored in a locked file cabinet on site, then transferred to the university office of the principal investigator.

ACEs. The ACE questions and Score (www.cdc.gov/ ace), developed by Dr. Anda following review of the literature and discussions with experienced researchers in the field, have good test-retest reliability (Dube, Williamson, Thompson, Felitti, \& Anda, 2004). ACE questions adapted from the Conflict Tactics Scale (Straus \& Gelles, 1990) were used to measure emotional and physical abuse, as well as domestic violence. Four ACE questions were adapted from Wyatt's (1985) measure of contact sexual abuse. Emotional and physical neglect ACE variables were taken from the Childhood Trauma Questionnaire (CTQ; Bernstein et al., 1994). The number of "yes" responses to each category is added to create an ACE Score. The ACE screening tool used in the current study was reviewed with front-line homeless agency staff to refine questions. The tool's item relating to violence against the respondent's mother was changed to any parent figure to elicit domestic violence experience. In the current study, internal consistency reliability for the 10 ACE items was analyzed using Cronbach's $\alpha$. The alpha score for the ACE instrument was .814, indicating strong internal consistency when using the sample of 224.

History of service utilization and helpfulness. Participants were asked if they used the following programs "for problems with emotions or nerves or your use of alcohol or drugs": support group or drop-in center, hospital emergency room, outpatient treatment program (mental health or substance abuse), healthcare center or doctor, religious program, program in jail, or other (identifying "other"). They indicated current age, approximate age at which they first used the service, and previous-year services used. Participants were asked to indicate whether the services were helpful, damaging, or made no difference to them. These questions were quantified by creating a dichotomous variable (helpful = yes; damaging or no difference $=$ no).

\section{Variables}

The 10 ACE items were dichotomous variables used to conduct descriptive and comparative analyses. For the logistic regression, the dependent variable is use of each program and independent variable is each ACE category. Demographic information served as control variables: age, gender, race, education, and substance abuse. Helpfulness of services was collapsed to a dichotomous variable, as stated above, to conduct descriptive analyses.

\section{Statistical Analyses}

Data was coded and entered into SPSS ${ }^{\circ} 17.0$ and STATA ${ }^{\circ}$ 10.0 by research team members for all statistical analyses. Descriptive analyses of age, ACEs, and service backgrounds used the sample of 224. Descriptive analyses of gender, age, race, education, and substance abuse used the 174 participants consenting to chart review. The Cronbach's a assessed internal consistency reliability for the 10 ACE items, and polychoric correlation analysis generated the binary correlation matrix on each $\mathrm{ACE}$ item. Correlations among ACEs and services and logistic regression analyses used the 174 participants with demographic characteristics. Binary logistic regressions estimated the association between each ACE and type of service use. Odds ratios and chi-square values were calculated to examine the relationship between ACEs and type of service use. Descriptive analyses examined the helpfulness of each type of service used.

\section{Results}

\section{Demographics}

Table 1 presents age range and gender composition of the 224 participants, 174 of whom granted permission to gather chart information. Demographic data on race, from 172 charts, reveals that most participants were White. Demographic data on education, from 164 charts, shows that most participants had no college degree, and more than half had the equivalent of high school or less. About $80 \%$ had a documented substance abuse history.

Respondents experienced a wide variety of ACEs, as indicated in Figure 1. About half suffered the loss of a biological parent, reported emotional neglect, had lived with a substance abuser, and reported emotional abuse. Table 2 indicates that over half of participants reported four or more ACEs, comparing respondent characteristics and ACE Scores. CA included more White males, and about one third of CA participants had some college education. Many more CA respondents had a documented substance abuse history. More than half of NY respondents were male, and nearly half were African American. Despite the differences in respondent characteristics presented in Table 2, more than half of both CA and NY groups reported ACE Scores of four and higher. Eighty-seven percent of people in the current sample indicated they had at least one ACE. Total ACE Score distribution did not show any significant differences between CA and NY-or for each ACE category, with the exception of household mental illness.

\section{Correlation Among ACEs and Services}

Binary correlation analyses were used to measure the strength of association between each ACE (see Table 3). All ACEs except for having an incarcerated family member were highly related to each other, which is consistent 
TABLE 1. Demographic and Regional Characteristics

\begin{tabular}{|c|c|c|c|}
\hline \multirow[b]{2}{*}{ Characteristics } & \multirow[b]{2}{*}{ Freq. (\%) } & \multicolumn{2}{|c|}{ Regions } \\
\hline & & CA (\%) & NY (\%) \\
\hline Age $(n=224)^{\text {a }}$ & & $n=137$ & $n=71$ \\
\hline $18-20$ & $11(5)$ & $5(3)$ & $4(6)$ \\
\hline $21-30$ & $27(12)$ & $10(7)$ & $11(16)$ \\
\hline $31-40$ & $44(20)$ & $27(20)$ & $15(21)$ \\
\hline $41-50$ & $75(33)$ & $45(33)$ & $26(37)$ \\
\hline $51-60$ & $55(25)$ & $40(29)$ & $13(18)$ \\
\hline $61-70$ & $10(4)$ & $9(7)$ & $1(1)$ \\
\hline $71-75$ & $2(1)$ & $1(1)$ & $1(1)$ \\
\hline Gender $(n=174)$ & & $n=123$ & $n=37$ \\
\hline Male & $101(58)$ & $79(64)$ & $22(60)$ \\
\hline Female & $73(42)$ & $44(36)$ & $15(40)$ \\
\hline Race $(n=172)$ & & $n=120$ & $n=37$ \\
\hline White & $118(69)$ & $95(78)$ & $16(43)$ \\
\hline African American/Black & $31(18)$ & $6(5)$ & $18(49)$ \\
\hline Hispanic & $4(2)$ & $1(1)$ & $3(8)$ \\
\hline Asian & $2(1)$ & $2(2)$ & \\
\hline $\begin{array}{l}\text { American Indian/Alaska } \\
\text { Native }\end{array}$ & $3(2)$ & $2(2)$ & \\
\hline More than one race & $12(7)$ & $12(10)$ & \\
\hline Other & $2(1)$ & $2(2)$ & \\
\hline Education $(n=164)$ & & $n=119$ & $n=34$ \\
\hline No high school diploma & $43(26)$ & $28(23)$ & $9(26)$ \\
\hline GED & $19(11)$ & $16(13)$ & $2(6)$ \\
\hline High school diploma & $47(29)$ & $26(22)$ & $17(50)$ \\
\hline Some college & $44(27)$ & $39(33)$ & $5(15)$ \\
\hline Associate's degree & $6(4)$ & $5(4)$ & $1(3)$ \\
\hline Bachelor's degree & $2(1)$ & $2(2)$ & \\
\hline Technical school & $3(2)$ & $3(3)$ & \\
\hline \multicolumn{2}{|c|}{ History of substance abuse $(n=134)$} & $n=123$ & $n=10$ \\
\hline Yes & $108(81)$ & $102(83)$ & $6(60)$ \\
\hline No & $26(19)$ & $21(17)$ & $4(40)$ \\
\hline
\end{tabular}

${ }^{\mathrm{a}} M=43.5(S D=11.99)$.
TABLE 2. ACE Score Distribution (Cumulative Percentages)

\begin{tabular}{lccc}
\hline & & \multicolumn{2}{c}{ Regions } \\
\cline { 3 - 4 } ACE & Percent $(\%)$ & CA \% & NY \% \\
Score & $(n=224)$ & $(n=137)$ & $(n=71)$ \\
\hline 0 & 13 & 12 & 17 \\
$0-1$ & 27 & 23 & 35 \\
$0-2$ & 36 & 36 & 54 \\
$0-3$ & 41 & 41 & 61 \\
$0-4$ & 54 & 54 & 65 \\
$0-5$ & 65 & 65 & 76 \\
$0-6$ & 77 & 77 & 80 \\
$0-7$ & 85 & 85 & 89 \\
$0-8$ & 93 & 93 & 92 \\
$0-9$ & 96 & 96 & 99 \\
$0-10$ & 100 & 100 & 100 \\
\hline
\end{tabular}

Note. ACE $=$ adverse childhood experience.

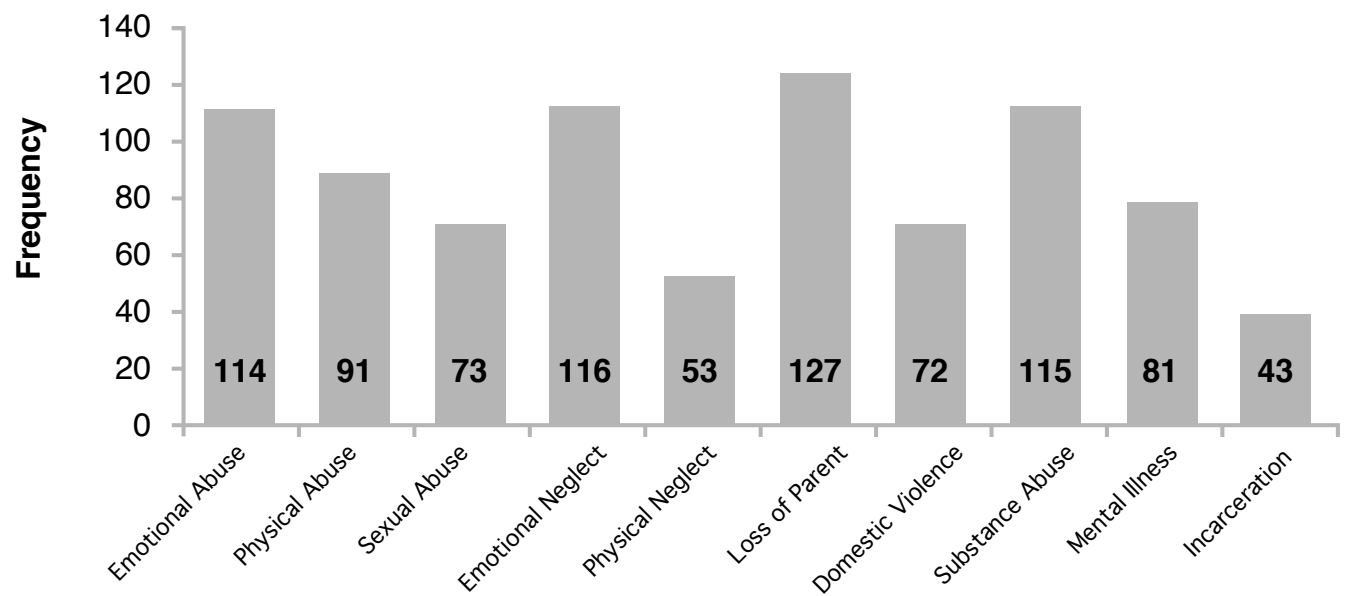

10 ACE Categories 
TABLE 3. Correlation of ACEs and Services

\begin{tabular}{|c|c|c|c|c|c|c|c|c|c|c|}
\hline$\overline{\mathrm{ACE}}$ & $\begin{array}{l}\text { 1. Emotional } \\
\text { abuse }\end{array}$ & $\begin{array}{l}\text { 2. Physical } \\
\text { abuse }\end{array}$ & $\begin{array}{l}\text { 3. Sexual } \\
\text { abuse }\end{array}$ & $\begin{array}{l}\text { 4. Lack of } \\
\text { family support }\end{array}$ & 5. Neglect & $\begin{array}{l}\text { 6. Loss } \\
\text { of parent }\end{array}$ & $\begin{array}{l}\text { 7. Domestic } \\
\text { violence }\end{array}$ & $\begin{array}{l}\text { 8. Substance } \\
\text { abuse }\end{array}$ & $\begin{array}{l}\text { 9. Mental } \\
\text { illness }\end{array}$ & 10. Incarceration \\
\hline $\begin{array}{l}\text { 1. Emotional } \\
\text { abuse }\end{array}$ & - & & & & & & & & & \\
\hline 2. Physical abuse & $.94^{* *}$ & - & & & & & & & & \\
\hline 3. Sexual abuse & $.60^{* *}$ & $.55^{\star *}$ & - & & & & & & & \\
\hline $\begin{array}{l}\text { 4. Lack of family } \\
\text { support }\end{array}$ & $.62^{* *}$ & $.58^{\star \star}$ & $.49^{* *}$ & - & & & & & & \\
\hline 5. Neglect & $.54^{\star *}$ & $.45^{\star *}$ & $.40^{* *}$ & $.78^{\star *}$ & - & & & & & \\
\hline 6. Loss of parent & $.55^{\star *}$ & $.44^{* *}$ & $.35^{*}$ & $.42^{* *}$ & $.39^{\star}$ & - & & & & \\
\hline $\begin{array}{l}\text { 7. Domestic } \\
\text { violence }\end{array}$ & $.74^{* *}$ & $.74^{\star *}$ & $.48^{* *}$ & $.45^{\star *}$ & $.49^{\star *}$ & $.34^{* *}$ & - & & & \\
\hline $\begin{array}{l}\text { 8. Substance } \\
\text { abuse }\end{array}$ & $.62^{\star *}$ & $.37^{\star *}$ & $.48^{* *}$ & $.35^{\star}$ & $.66^{* *}$ & $.20^{*}$ & $.50^{* *}$ & - & & \\
\hline 9. Mental illness & $.57^{\star \star}$ & $.53^{\star *}$ & $.53^{* *}$ & $.67^{\star *}$ & $.74^{\star *}$ & $.32^{* *}$ & $.47^{\star \star}$ & $.55^{\star \star}$ & - & \\
\hline 10. Incarceration & $.08^{*}$ & $.18^{*}$ & $.16^{*}$ & $.21^{*}$ & $.23^{*}$ & $.15^{*}$ & $.04^{*}$ & $.33^{*}$ & $.20^{*}$ & - \\
\hline \multicolumn{11}{|l|}{ Type of Service } \\
\hline Support group & .09 & .12 & -.09 & .05 & .01 & $.33^{*}$ & .03 & .13 & .07 & -.13 \\
\hline Emergency & -.01 & .11 & .13 & .09 & .12 & .10 & .13 & .11 & .13 & -.04 \\
\hline Outpatient & .01 & .14 & .12 & .01 & -.03 & $.32^{*}$ & $.21^{\star}$ & $.28^{\star}$ & .07 & .10 \\
\hline $\begin{array}{l}\text { Health care } \\
\text { services }\end{array}$ & $.20^{*}$ & $.26^{*}$ & $.26^{*}$ & $.27^{\star}$ & .09 & $.25^{*}$ & $.22^{*}$ & .16 & $.27^{*}$ & -.17 \\
\hline $\begin{array}{l}\text { Religious } \\
\text { program }\end{array}$ & .01 & $.01^{*}$ & .02 & -.05 & $.25^{\star}$ & .11 & .02 & .03 & -.05 & .11 \\
\hline Jail program & .08 & .15 & -.06 & .08 & -.01 & .14 & .03 & $.24^{*}$ & .06 & .03 \\
\hline
\end{tabular}

Note. ACE $=$ adverse childhood experience. ${ }^{\star} p<.05 ;{ }^{* *} p<.001$.

TABLE 4. Odds Ratio Between ACE Category and Significance and Helpfulness for Service Used

\begin{tabular}{|c|c|c|c|c|}
\hline Type of service & $\mathrm{ACE}$ & OR & $95 \% \mathrm{CI}$ & \% Helpfulness \\
\hline \multicolumn{5}{|c|}{ Interpersonal prevention services } \\
\hline \multicolumn{5}{|c|}{ Support group program } \\
\hline & Loss of parent & $2.40^{* *}$ & $1.36-4.24$ & 78 \\
\hline \multicolumn{5}{|c|}{ Religious program } \\
\hline & Emotional neglect & $2.09^{* *}$ & $1.04-4.17$ & 54 \\
\hline \multicolumn{5}{|l|}{ Clinical services } \\
\hline \multicolumn{5}{|c|}{ Outpatient treatment program } \\
\hline & Loss of parent & $2.34^{* *}$ & $1.35-4.07$ & 71 \\
\hline & Domestic violence & $1.79^{\star *}$ & $1.32-2.41$ & 77 \\
\hline & Sexual abuse & $1.98^{* *}$ & $1.15-3.42$ & 72 \\
\hline \multicolumn{5}{|c|}{ Health care services } \\
\hline & Mental illness & $2.09^{* *}$ & $1.18-3.72$ & 79 \\
\hline & Emotional neglect & $2.02^{\star *}$ & $1.16-3.52$ & 81 \\
\hline & Physical abuse & $2.01^{\star \star}$ & $1.15-3.51$ & 81 \\
\hline & Sexual abuse & $2.02^{\star *}$ & $1.12-3.61$ & 79 \\
\hline & Domestic violence & $1.86^{\star}$ & $1.03-3.37$ & 80 \\
\hline & Loss of parent & $1.93^{\star *}$ & $1.11-3.37$ & 79 \\
\hline & Emotional abuse & $1.71^{\star}$ & $0.99-2.96$ & 80 \\
\hline \multicolumn{5}{|c|}{ Criminal justice services } \\
\hline \multicolumn{5}{|l|}{ Jail program } \\
\hline & Substance abuse & $1.94^{\star *}$ & $1.05-3.58$ & 51 \\
\hline
\end{tabular}


with the high number of ACEs per person. The level of use of service to intervene with each ACE was lower. The most common services were outpatient (used for loss of a biological parent), health care (used for loss of a biological parent; living with a mentally ill household member; emotional neglect; and physical, sexual, and emotional abuse), and support group (used for loss of a biological parent).

\section{Logistic Regression Analysis}

Binary logistic regression analyses were used to determine whether there was a predictive relationship between each ACE and types of service use, controlling for demographic characteristics (see Table 4). The log odds of support group use shows that respondents who lost their parent were more than twice as likely to use these services than those who did not report this ACE. The relative frequency of religious program use among respondents who reported emotional neglect was twice that of those who did not report this ACE. Thus, interpersonal prevention programs, such as social support groups and faith-based supports, were used more often by participants who reported loss of a parent or emotional neglect. Outpatient treatment was used more than twice as often by respondents who lost a parent. The odds of outpatient treatment use by respondents reporting sexual abuse was about twice that of other respondents. The average relative frequency of health care service use among respondents who reported the ACEs of a family member experiencing mental illness, emotional neglect, physical abuse, sexual abuse, domestic violence, loss of a biological parent, or emotional abuse was about twice that of respondents who did not report these ACEs. Respondents with a substance abusing family member were about twice as likely to use services within a jail program. The rightmost column in Table 4 reports the level of helpfulness. The base was persons who reported the ACE and use of service for it. For example, among 83 people who used a support group to deal with loss of a parent, $78 \%$ found the support group helpful. Of respondents reporting the ACE and the service use predicted by that ACE, $51-81 \%$ also reported that the service was helpful, in most cases, more than $70 \%$.

\section{Discussion}

Retrospective reports of ACEs are common among the people experiencing homelessness who participated in this study. Eighty-seven percent reported at least one of 10 ACEs, and more than half reported four or more ACEs. In contrast, the original ACE Study found that $52 \%$ reported one or more ACE, and 6\% had ACE Scores of four or higher (Felitti et al., 1998). In a study of demographically representative samples from five states, Bynum and colleagues (2010) found that $59 \%$ of participants had one or more ACE, with five or more ACEs reported by close to $9 \%$. Approximately half of respondents in the current study re- ported each of the following: loss of a parent, emotional neglect, a substance abusing family member, and emotional abuse. These findings on the full range of ACEs reported by people experiencing homelessness extends ACE research and fills a gap, confirming suggestions that ACEs increase risk of homelessness (Burt, 2001; Herman et al., 1997). The current study also found that ACEs are correlated with one another, bolstering findings demonstrating that ACEs often co-occur (Dong et al., 2004). If ACEs and subsequent health risk behaviors impede healthy developmental processes and create a pathway to multiple problems (Larkin \& Records, 2007), then ACEs may increase vulnerability to systemic challenges creating conditions for loss of employment and housing (Burt, 2001).

The conceptual framework that drove the current study brings attention to multiple developmental processes that take place within the context of culture and systems (Larkin \& Records, 2007; Robbins, Chatterjee, \& Canda, 2012; Wilber, 2000). This view helps to recognize that while ACEs may increase the risk for homelessness, people possess various areas of strength that can be supported. Responsive services and social networks, for example, have the potential to enhance inner resilience with outer resources, promoting recovery (Larkin, Beckos, \& Shields, 2012; Smith \& Carlson, 1997; Starnino, 2009). The current study found that ACEs predict types of services used for "problems with emotions or nerves or your use of alcohol or drugs" prior to becoming homeless. Support groups (interpersonal prevention services) were more likely to be used by people who experienced emotional neglect or lost a parent. While this finding may seem unsurprising, the current study represents an early step in exploring service use backgrounds among people experiencing homelessness. It is useful to see that people who felt the need for a service (related to a particular ACE) were more likely to access it than those who did not have the same ACE. This suggests an opportunity for ACE-informed interventions before people become homeless. People experiencing homelessness who previously sought help for emotional and substance abuse issues, which appear to be strongly associated with ACEs, often felt that their use of services was helpful. Yet, for them, these services did not successfully prevent homelessness, calling for research on the efficacy of programs serving high ACE Score populations. Thus, there is also a need to further explore perceptions of service helpfulness and examine which individuals are unlikely to access or use services.

\section{Limitations}

The current study is limited by its cross-sectional retrospective design, as well as the use of a convenience sample and reliance on self-report as the only data collection modality. People may attribute challenging circumstances to earlier experiences. On the other hand, Felitti and colleagues (1998) suggest ACEs can be hidden and underre- 
ported. There was the possibility of a selection bias with more disabled clients choosing not to participate. Participants may have been more likely to state that services were helpful when they were being asked by service providers. This sample does not reflect people who avoided services, and the brief questionnaire captured specific and limited information from those using services. Yet, logistic analyses reveal significant relationships between each ACE and service use. By controlling for demographic information, the direct relationship is clear between the ACE and the service used. Because the study design does not involve comparison groups, more rigorous research is needed to clarify whether people experiencing homelessness have more ACEs or if those who received effective service did not become homeless. The convenience sample is not generalizable, so participants in this study may not be representative of people experiencing homelessness or those who do not access shelter system services. Yet, there is little difference in overall ACE Score or specific ACE category when comparing NY and CA respondents, demonstrating consistent reports of ACE backgrounds among people experiencing homelessness. Furthermore, when these findings are combined with the ACE Study findings (Felitti et al., 1998), the knowledge of multiple problems associated with homelessness (Burt, 2001), and an understanding of the interplay of risks and resources (Smith \& Carlson, 1997), the conceptual framework driving the current research points to an opportunity to reduce vulnerability to homelessness through the provision of effective earlier support geared toward preventing ACEs and their consequences (Larkin \& Records, 2007).

\section{Implications for Homelessness Prevention and Research}

ACEs were more common among participants of the current study than middle-class participants of the ACE Study, and ACEs predicted services used prior to becoming homeless. According to the U.S. Department of Housing and Urban Development (2011), family homelessness is the fastest growing segment of the homeless population. The conceptual framework of the current study suggests that adequate support for adults with high ACE Scores, who are at risk or experiencing homelessness, can help prevent intergenerational ACE transmission (Larkin \& Records, 2007). Among high ACE Score groups experiencing multiple problems, homelessness may be reduced by improving access to services that intervene with ACE consequences. This can be achieved through investments in family-centered services that include peer supports (Briar-Lawson, 1998). We recommend that psychosocial intakes examine ACEs. ACE-informed programming, designed to mobilize resilience and recovery among high ACE Score populations, may prevent homelessness by strengthening families and communities (Larkin, Beckos, \& Shields, 2012).
Social workers and other agency, community, or policy leaders could raise awareness of ACEs and their consequences in agencies, schools, and neighborhoods. Capacity building includes information sharing through presentations, websites, and social media. These tools could support application of ACE response knowledge by policymakers, agency directors, helping professionals, and community members. ACE Think Tank and Action Teams (Adverse Childhood Experiences, 2011; see http://www.aceresponse.org) mobilize these endeavors by strengthening social networks and identifying leaders in local agencies and communities to combine forces toward ACE response. Policymakers interested in reducing the societal costs of homelessness have an opportunity to promote the development and evaluation of programs responding to ACEs sooner.

Restorative integral support (RIS) is a comprehensive approach that embodies these recommendations (Larkin, Beckos, \& Shields, 2012). Transcending and including a data-informed practice process (Duffee, 2010) and the social work integral model (Garner, 2011), RIS explicitly draws on Wilber's (2000) integral theory (Robbins, Chatterjee, \& Canda, 2012; Starnino, 2009; Thomas, 2004) to guide and evaluate ACE response (Larkin \& Records, 2007). RIS implementation involves the following practical steps:

- Raise staff awareness of ACE Score characteristics among families and communities served (e.g., share ACE research findings and examine ACEs during intake)

- Integrate resilience and recovery knowledge that informs ACE response (e.g., design policies to facilitate peer-support networks that mobilize resilience and offer mutual aid for recovery)

- Support staff self-care to prevent vicarious trauma as well as to promote positive role modeling and relationship-building with clients (e.g., direct resources toward restorative agency cultures)

- Engage staff in articulating values and principles of ACE-informed programs (e.g., family-centered, integrated, recovery-oriented)

- Identify combinations of best practices, drawing on staff skills and local resources to address ACE Score characteristics of families and communities served (e.g., identify how evidence supported interventions and emerging practices address ACEs or ACE consequences)

- Advocate for policymakers and funding sources to prioritize the development of ACE-informed programs by investing adequate societal resources now to save costs later (e.g., create ACE Think Tank and Action Teams to facilitate group efforts)

- Develop team-based research partnerships to determine impact 
The current study includes many of Healthy People's leading health indicators-substance abuse, mental health, injury and violence, environmental quality, and access to health care-informing national health goals (2010; see www.healthypeople.gov). Future research could explore the interaction of ACE Scores with coping skills, social networks, and access to services among vulnerable groups, such as older people, who are living in poverty. Another next step would be the development of a scale to assess level of service system integration, which would help study whether comprehensive service delivery contributes to better access and outcomes for multi-problem groups with higher ACE Scores. Qualitative research investigating perceived service helpfulness might shed light on service characteristics contributing to engagement and positive experiences that could be mobilized to deliver ACE-responsive services more helpful in reducing risk for homelessness. The current study also lays the groundwork for practice research on ACE-informed program responses, such as those facilitated by the RIS model, that address leading health indicators.

\section{Conclusion}

ACEs are strongly associated with later-life health and social problems (Felitti et al., 1998) that play a role in homelessness (Burt, 2001). More than half of people experiencing homelessness in the current sample reported four or more ACEs. ACEs predicted types of services used for emotional or substance abuse problems prior to becoming homeless, suggesting opportunities to address ACEs sooner. Practical steps for ACE response with families and communities seek to reduce homelessness and break intergenerational ACE transmission. Future research recommendations include an exploration of ACEs and resources among other vulnerable groups, development of a service integration measurement scale, study of perceived service helpfulness, and practice research on ACE-informed programs.

\section{References}

Adverse Childhood Experiences. (2011, November 11). About us [Web page]. Retrieved from http://www.aceresponse.org/ aboutus.html

Bernstein, D. P., Fink, L., Handelsman, L., Foote, J., Lovejoy, M., Wenzel, K.,...Ruggiero, J. (1994). Initial reliability and validity of a new retrospective measure of child abuse and neglect. American Journal of Psychiatry, 151, 1132-1136.

Briar-Lawson, K. (1998). Capacity building for integrated familycentered practice. Social Work, 43, 539-549.

Burt, M. (2001). What will it take to end homelessness? Washington, DC: Urban Institute.

Bynum, L., Griffin, T., Ridings, D. L., Wynkoop, K. S., Anda, R. F., Edwards, V. J.,...Croft, J. B. (2010). Adverse Childhood Experiences Reported by Adults-Five States, 2009. MMWR: Morbidity \& Mortality Weekly Report, 59(49), 1609-1613.
Capital District Regional Planning Commission. (2011, November 11). Capital District Minor Civil Divisions. Retrieved from http://www.cdrpc.org/municip.html\#Estimates

Christensen, R. C., Hodgkins, C. C., Garces, L. K., Estlund, K. L., Miller, M. D., \& Touchton, R. (2005). Homeless, mentally ill and addicted: The need for abuse and trauma services. Journal of Health Care for the Poor and Underserved, 16(4), 615-621.

Dong, M., Anda, R. F., Felitti, V. J., Dube, S. R., Williamson, D. F., Thompson, T. J.,...Giles, W. H. (2004). The interrelatedness of multiple forms of childhood abuse, neglect, and household dysfunction. Child Abuse \& Neglect, 28, 771-784.

Dube, S. R., Williamson, D. F., Thompson, T., Felitti, V. J., \& Anda, R. F. (2004). Assessing the reliability of retrospective reports of adverse childhood experiences among adult HMO members attending a primary care clinic. Child Abuse \& Neglect, 28(7), 729-737.

Duffee, D. E. (2010). Knowledge to practice or knowledge of practice? A comparison of two approaches to bringing science to service. In M. D. Krohn, A. J. Lizotte, \& G. P. Hall (Eds.), Handbook on crime and deviance. New York, NY: Springer.

Felitti, V. J., Anda, R. F., Nordenberg, D., Williamson, D. F., Spitz, A. M., Edwards, V.,....Marks, J. S. (1998). Relationship of childhood abuse and household dysfunction to many of the leading causes of death in adults: The adverse childhood experiences (ACE) Study. American Journal of Preventative Medicine, 14(4), 354-364.

Freund, P. D., \& Hawkins, D. W. (2004). What street people reported about service access and drug treatment. Journal of Health \& Social Policy, 18(3), 87-93.

Garner, M. D. (2011). Thinking practice: The social work integral model. Families in Society: The Journal of Contemporary Social Services, 92(3), 255-261. doi: 10.1606/1044-3894.4128

Germain, C. B., \& Gitterman, A. (1980). The life model of social work practice: Advances in theory \& practice. New York, NY: Columbia University Press.

Green, D. M. (2005). History, discussion, and review of a best practices model for service delivery for the homeless. Social Work in Mental Health, 3(4), 1-16.

Healthy People. (2010, November 9). About Healthy People [Web page]. Retrieved from http://www.healthypeople.gov/2020/ about/default.aspx

Herman, D. B., Susser, E. S., Struening, E. L., \& Link, B. L. (1997). Adverse childhood experiences: Are they risk factors for adult homelessness? American Journal of Public Health, 87(2), 249-255.

Key to the City: USA City Information for nearly every city \& town in the USA. (2011, November 11). Petalum, Sonoma County, California [Web page]. Retrieved from http://www. usacitiesonline.com/cacountypetaluma.htm

Kim, M. M., Ford, J. D., Howard, D. L., \& Bradford, D. W. (2010). Assessing trauma, substance abuse, and mental health in a sample of men experiencing homelessness. Health \& Social Work, 35(1), 39-48.

Larkin, H. (2006). Social work as an integral profession. AQAL: The Journal of Integral Theory and Practice, 1(2), 320-350.

Larkin, H., Beckos, B., \& Shields, J. J. (2012). Mobilizing resilience and recovery in response to adverse childhood experiences (ACE): A restorative integral support (RIS) case study. Journal of Prevention \& Intervention in the Community, 40(4).

Larkin, H., Felitti, V. J., \& Anda, R. F. (in press). Social work and adverse childhood experiences (ACE) research: Implications for practice and health policy. Social Work in Public Health.

Larkin, H., \& Records, J. (2007). Adverse childhood experiences: Overview, response strategies, and Integral Theory. Journal of Integral Theory and Practice, 2(3), 1-25.

North, C. S., Pollio, D. E., Perron, B., Eyrich, K. M., \& Spitznagel, E. L. (2005). The role of organizational characteristics in determining patterns of utilization for substance abuse, mental health, and shelter by people experiencing homelessness. Journal of Drug Issues, 35(3), 575-592. 
Padgett, D. K., Hawkins, R. L., Abrams, C., \& Davis, A. (2006). In their own words: Trauma and substance abuse in the lives of formerly homeless women with serious mental illness. American Journal of Orthopsychiatry, 76(4), 461-467.

Robbins, S. B., Chatterjee, P., \& Canda, E. R. (2012). Contemporary human behavior theory: A critical perspective for social work (3rd ed.). Upper Saddle River, NJ: Allyn \& Bacon.

Rosenheck, R. A., Lam, J., Morrissey, J. P., Calloway, M. O., Stolar, M., Randolph, F., \& the ACCESS National Evaluation Team. (2002). Service systems integration and outcomes for mentally ill homeless persons in the ACCESS program. Psychiatric Services, 53(8), 958-966.

Smith, C., \& Carlson, B. E. (1997). Stress, coping, and resilience in children and youth. Social Service Review, 71(2), 231-256.

Starnino, V. (2009). An integral approach to mental health recovery: Implications for social work. Journal of Human Behavior in the Social Environment, 19, 820-842.

Straus, M., \& Gelles, R. J. (1990) Physical violence in American families: Risk factors and adaptations to violence in 8,145 families. New Brunswick, NJ: Transaction Press.

Tam, T. W., Zlonick, C., \& Robertson, M. J. (2003). Longitudinal perspective: Adverse childhood events, substance use, and labor force participation among homeless adults. The American Journal of Drug and Alcohol Abuse, 29(4), 829-846.

Thomas, P. E. (2004). Toward the development of an integral approach to social work: Implications for human behavior theory and research. Journal of Human Behavior in the Social Environment, 9(3), 1-19.

U.S. Census Bureau. (2010a). State \& County QuickFacts [Albany County, New York]. Retrieved from http://quickfacts.census. gov/qfd/states/36/36001.html
U.S. Census Bureau. (2010b). State \& County QuickFacts [Sonoma County, California]. Retrieved from http://quickfacts.census. gov/qfd/states/06/06097.html

U.S. Department of Housing and Urban Development. (2011). The 2010 Annual Homeless Assessment Report to Congress. Retrieved from http://www.hudhre.info/documents/2010Home lessAssessmentReport.pdf

Wilber, K. (2000). A theory of everything. Boston, MA: Shambhala.

Wyatt, G. E. (1985). The sexual abuse of Afro-American and WhiteAmerican women in childhood. Child Abuse \& Neglect, 9, 507-519.

Zlotnick, C., Tam, T., \& Robertson, M. J. (2004). Adverse childhood events, substance abuse, and measures of affiliation. Addictive Behaviors, 29(6), 1177-1181.

Heather Larkin, PhD, LCSW-R, assistant professor, and Jihyun Park, PhD, MSW, research fellow, School of Social Welfare, University at Albany, SUNY. Correspondence: hlarkin@albany.edu; University at Albany, 135 Western Ave., Albany, NY 12222.

Authors' note. We extend our gratitude to the agency staff and program participants.

Manuscript received: July 22, 2011

Revised: November 17, 2011

Accepted: November 21, 2011

Disposition editor: Christopher G. Petr

\section{Your colleagues agree...}

Families in Society is an excellent resource for tools and information about staff training, professional learning, program development, and evaluation services.

\section{"The article on Dine (Navajo) natural helping and resilience is an excellent resource for our early childhood care and development initiative." \\ Jaime Apolonio First Nations Partnership Programs}

"The article on foster parent decision-making has been very helpful in providing information and statistics on the effectiveness of recruitment and retention of foster parents."

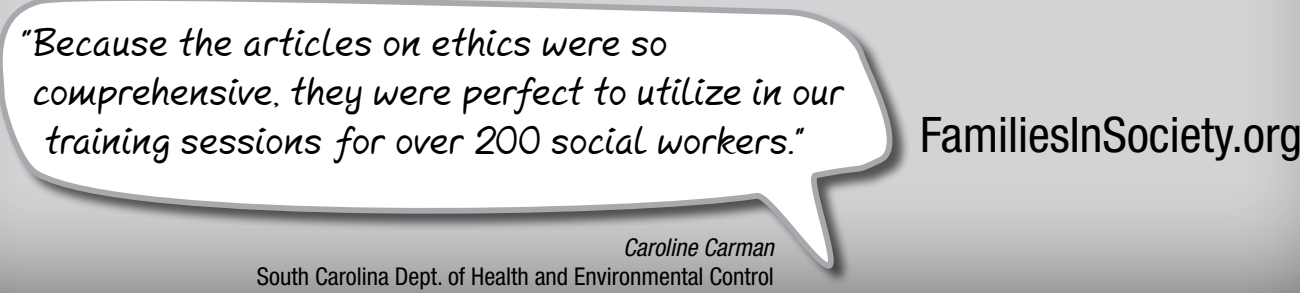

South Carolina Dept. of Health and Environmental Control 